\title{
MICROEMPRESA FAMILIAR: DIFICULDADES NO PROCESSO SUCESSÓRIO E 0 PERFIL EMPREENDEDOR DO POSSÍVEL SUCESSOR
}

Aline Gonçalves Piciula Silva; Rafael Leonardo Freitas de Souza; Josélia Galiciano Pedro.

Universidade do Oeste Paulista - UNOESTE, Curso Administração. E-mail: joselia@unoeste.br

\section{RESUMO}

O presente artigo aborda as dificuldades enfrentadas no processo sucessório de uma microempresa familiar, que foi iniciada pelo empreendedor para tentar melhorar a vida socioeconômica do fundador. Após o início da empresa o fundador esteve focado em implementar e desenvolver o seu negócio, mas também deseja que alguém o substitua dando segmento ao o que ele fez em sua trajetória pela empresa, esse é um assunto que tem gerado vários estudos relacionados, porque é um dos principais motivos do fechamento das empresas. Desta forma, o processo sucessório causa inúmeras dificuldades para o fundador da empresa familiar. A investigação justifica-se pelo fato da maioria das empresas através dos seus fundadores enfrentarem dificuldades durante e no processo de sucessão familiar, auxiliando e alertando os micro empreendedores de uma etapa natural de uma empresa. Sendo assim, este estudo teve como objetivo identificar as dificuldades encontradas pelas microempresas familiares durante o processo sucessório e verificar se os possíveis sucessores tem perfil empreendedor. Como metodologia o estudo teve como abordagem a pesquisa qualitativa com aplicação de questionários e quantitativa, como característica o estudo de caso, sendo o tipo de pesquisa a exploratória, pesquisa bibliográfica. Desta forma o presente artigo demonstrou as empresas familiares que estão no mercado e também as que pretendem iniciar, a importância de um planejamento para o processo sucessório, e também em qual momento do ciclo de vida empresa está transição deve acontecer.

Palavras-chave: Empreendedorismo. Empresa Familiar. Processo Sucessório. Perfil Empreendedor.

\section{MICROENTERPRISE FAMILY: DIFFICULTIES NOT SUCCESSORY PROCESS AND THE PROFILE OF THE POSSIBLE SUCCESSOR}

\begin{abstract}
This article addresses the difficulties faced in the succession process of a family microenterprise, which was initiated by the entrepreneur to try to improve the socioeconomic life of the founder. After the start of the company, the founder was focused on implementing and developing his business, but also wants someone to replace him by giving a segment to what he did in his trajectory by the company, this is a subject that has generated several related studies, because it is One of the main reasons for the closure of companies. In this way, the inheritance process causes numerous difficulties for the founder of the family business. The investigation is justified by the fact that most of the companies through their founders face difficulties during and in the process of family succession, helping and alerting the micro entrepreneurs of a natural stage of a company. Thus, this study aimed to identify the difficulties encountered by family microenterprises during the succession process and to verify if possible successors have an entrepreneurial profile. As methodology, the study had as approach the qualitative research with application of questionnaires and quantitative, as characteristic the case study, being the type of research the exploratory, bibliographical research. In this way the present article demonstrated the family companies that are in the market and also those that intend to start, the importance of a planning for the succession process, and also in which moment of the life cycle company is transition should happen.
\end{abstract}

Keywords: Entrepreneurship. Family business. Succession Process. Profile Entrepreneur. 


\section{INTRODUÇÃO}

As empresas familiares estão presentes em vários setores do mercado, na oferta de produtos e ou serviços, desta forma, pode-se perceber a importância das empresas familiares para a economia do país, pois são geradoras de tributos e empregos participando do desenvolvimento do país. As empresas podem classificadas como de grande, médio, de pequeno ou micro porte, sendo que a maioria enquadra-se como Micro ou Pequena Empresa (MPE). Tendo em vista que dos 6,4 milhões de negócios existentes no Brasil, 99\% são MPEs elas geram no setor privado $52 \%$ dos empregos com carteira assinada, 3,7 milhões delas são $\mathrm{MEI}$, Micro Empresa Individuais (SEBRAE, 2016). E de acordo com SEBRAE (2015) 90\% das empresas se caracterizam como empresa familiar.

Assim o fundador que, nada mais é do que um empreendedor está preocupado com o desenvolvimento e consolidação do negócio e que ela gere lucro, porém, com o amadurecimento da empresa haverá a necessidade de encontrar um sucessor, que com o qual deseja que ele mantenha os princípios, valores e culturas que foram o alicerce para 0 crescimento da empresa, vendo nos membros mais próximos de sua família uma das possibilidades de sucessão, como os filhos, esposas e genros, neste momento começam a surgir os desafios e dificuldades, lembrando de que existe também a possibilidade de falta precoce do fundador.

Mas nem sempre os sucessores se identificam com o tipo de negócio do fundador, pois muitas vezes não atendem as expectativas e não tem características para dirigir a empresa, ou não se identificam com o cargo a que está sendo repassado, por não possuir o espírito empreendedor, sendo estes fatores indispensáveis para a continuidade do negócio.

Porém, o que pode ocorrer é o fundador estar focado integramente no negócio da empresa e acabar esquecendo-se, ou não se preocupando com o processo sucessório, desta forma, essas dificuldades podem gerar uma grande possibilidade de fechamento da empresa, tendo em vista que este possa ser o meio principal de fonte de renda da família.

Tendo em vista as barreiras e limitações encontradas na condução do processo sucessório. Este estudo justifica-se pelo fato da maioria das empresas através dos seus fundadores enfrentarem dificuldades durante e no processo de sucessão familiar.

Neste contexto o presente artigo tem como problemática: quais são as dificuldades encontradas pelas microempresas familiares durante o processo sucessório? $E$ se os sucessores possuem o perfil empreendedor?

Acredita-se que a maior parte das empresas familiares não estão preparadas para o processo sucessório, e as que possuem um possível sucessor, este não possui o perfil empreendedor ou não estão aptos para assumir tal posição.

O estudo tem objetivo geral: identificar as dificuldades encontradas pelas microempresas familiares durante $\mathrm{o}$ processo sucessório e verificar se os possíveis sucessores tem perfil empreendedor.

Os objetivos específicos buscam: pontuar as dificuldades encontradas para o processo sucessório; identificar as dificuldades existentes nas microempresas durante 0 processo sucessório; levantar quais são as características do perfil empreendedor; resgatar conceitos de empresa familiar; identificar em qual estágio do ciclo de vida da empresa é necessário se pensar no processo de sucessão.

\section{MÉTODOS}

A metodologia é composta por vários métodos que combinados formam um processo, que visa guiar para a discussão das premissas básicas do estudo, baseados em regras e procedimentos científicos.

Neste estudo foi aplicado à abordagem qualitativa, pois "Utilizamos a pesquisa qualitativa quando queremos descrever nosso objeto de estudo com mais profundidade. Por isso, ela é muito comum em estudos sobre o comportamento de um indivíduo ou de um grupo social" (MASCARENHAS, 2012, p. 46). Assim, a pesquisa qualitativa é uma maneira de verificar como uma pessoa ou grupo se comporta, através do analise e da descrição da questão.

A característica do estudo foi o estudo de caso em uma microempresa do setor alimentício que atua há quase vinte anos na Região de Presidente Prudente, onde segundo Gil (2012, p. 58) define que, "Estudo de caso é caracterizado pelo estudo profundo e exaustivo de um ou de poucos objetos, de maneira a permitir o seu conhecimento amplo detalhado, tarefa praticamente impossível mediante os outros tipos de delineamentos considerados". Desta 
forma, o estudo de caso se caracteriza por uma análise mais criteriosa podendo assim se ter uma visão mais abrangente do problema abordado.

Dos tipos de pesquisa, foi utilizada a pesquisa exploratória onde segundo Gil (2012, p. 27), "Pesquisa exploratória tem como principal finalidade desenvolver, esclarecer e modificar conceitos e ideias, tendo em vista a formulação de problemas mais precisos ou hipóteses pesquisáveis para estudos posteriores". Entendese que pesquisa exploratória é um meio de compreender o assunto abordado a fim de orientar novos estudos.

Esse estudo utilizou como método para coleta de dados a pesquisa bibliográfica e aplicação de questionário.

Foram utilizadas fontes secundários de dados como pesquisa bibliográfica em livros, revistas, pesquisas, teses, pois segundo Lakatos (2010), a pesquisa bibliográfica é uma forma de coletas de dados, obtidas através do que já foi divulgado em diversos meios de comunicação.

Assim, foram aplicados questionários para o empresário e sua possível sucessora, afim identificar a opinião dos entrevistados, que Segundo Gil (2012), questionário é a técnica de investigação composta por um conjunto de questões que são submetidas a pessoas com o propósito de obter informação sobre conhecimento, crenças, sentimentos, valores, interesses, expectativas, aspirações, temores, comportamentos presente ou passado.

A organização e análise dos dados desta investigação foram realizadas por meio de quatro etapas: 1a etapa. Leitura preliminar e revisão bibliográfica junto aos principais autores, permitindo os pesquisadores conhecer 0 material, apreender informações importantes da pesquisa; 2a etapa. Aplicação do questionário junto aos sujeitos da pesquisa, desta forma, foram analisados o conteúdo a partir dos dados brutos, ou seja, criando um eixo condutor entre a teoria e a prática; 3 a etapa. Fase de interpretação dos resultados, após a revisão bibliográfica e aplicação dos questionários. Foram analisados segundo a pesquisa qualitativa verificar o papel do empreendedor na empresa familiar. 4a etapa. Por fim, foram sugeridas eventuais melhorias no processo da empresa pesquisada.

\section{EMPRESAS FAMILIARES E SUA IMPORTÂNCIA PARA O PAÍS}

As empresas familiares possuem um importante papel dentro da sociedade onde, "De maneira geral, pode-se considerar que as empresas familiares correspondem a mais de $4 / 5$ da quantidade das empresas privadas brasileiras e respondem por mais de $3 / 5$ da receita e $2 / 3$ dos empregos quando se considera 0 total das empresas privadas brasileiras". (OLIVEIRA, 2010, p. 8).

Desta forma as empresas familiares são maioria entre as empresas privadas, e grande geradora de empregos. São de extrema importância para o meio econômico do país, pois segundo Oliveira $(2010$, p. 5), "de qualquer forma, o desenvolvimento da empresa familiar é um assunto de elevada importância para o futuro da economia do país [...]", por isso é um assunto que requer uma profunda análise, para que as empresas permaneçam e que gerem bons frutos para contribuição do desenvolvimento do país.

Os negócios que tem como base a família podem evoluir, pois, "as empresas familiares estão presentes no mundo todo. Normalmente são identificadas apenas como de pequeno porte, mas se desenvolvem e podem tornar-se grandes organizações." (MOREIRA JUNIOR, 2011, p. 1), ou seja, o que hoje é pequeno amanhã poderá se tornar grande.

\subsection{CONCEITO DE MICROEMPRESA E EMPRESA FAMILIAR}

As empresas são classificadas de maneira que a distingue uma das outras, desta forma:

O SEBRAE, por sua vez, classifica como microempresa aquela que emprega até nove pessoas, no caso do comércio e serviços, ou até 19 , no caso dos setores industrial ou de construção. Pequena empresa é aquela que emprega de 10 a 49 pessoas (comércio e serviços) ou de 20 a 99 (indústria $\mathrm{e}$ construção). (SEBRAE apud WANKE, 2012, p. 2).

Com isso é definido uma das formas de considerar o que é uma microempresa, que seriam pela quantidade de colaboradores que ela contrata.

Outra maneira de definir uma microempresa é por sua rentabilidade que, de 
acordo com Almeida (2009, p. 31) "é considerada micro empresa o empresário, a pessoa jurídica, ou a ela equiparada, que aufira, em cada anocalendário, receita bruta igual ou inferior a $\mathrm{R} \$$ 240.000,00 (duzentos e quarenta mil reais)." Contudo, o negócio para se enquadrar como microempresa deve ter um faturamento anual que não ultrapasse $R \$ 240.000,00$, valor este estipulado para a definição da empresa nesta categoria.

Essas empresas tem reflexo notório na contratação de mão de obra, [...] "são as microempresas e empresas de pequeno porte as responsáveis pela contratação de número expressivo de obreiros, merecendo, por isso mesmo, especial atenção do Estado[...]".(ALMEIDA 2009, p. 14). Assim, notase a importância destas categorias de empresas na geração de empregos no país e também para a economia, que permite a elas um tratamento diferenciado pelo estado.

Já se tratando de empresa familiar é definido que a empresa familiar quando iniciada, seu fundador tem atributos específicos para implantar e desenvolver o seu negócio, que é ser um empreendedor, com isso ele a criou, fez crescer e que quando não estiver mais presente por algum motivo sua família assumirá, dará seguimento ao negócio. (WERNER, 2004), sendo está uma característica de uma empresa familiar, quando o fundador almeja passar seu empreendimento para um membro de sua família.

Elas são negócios que surgem por diversos motivos a partir de alguma necessidade ou oportunidades que, "[...] tem o objetivo de melhorar a condição socioeconômica de uma família" (MAXIMIANO, 2012, p. 30), então quando o fundador inicia a sua empresa seu principal objetivo é para o sustento familiar.

De acordo com Schneider (2012) empreendimentos iniciados por necessidades são aquele que precisam de uma geração de renda para sua família, pois não tem outra forma de sustento, esses tipos de empreendedores correm mais riscos em seus negócios por não ser algo planejado, porém existem alguns que conseguem se alavancar. No entanto também existe o empreendedor por oportunidades, que é aquele que consegue ter visão de mercado e se programar para tal decisão de forma organizada e estruturada.

Mas entre as empresas que trabalham em família existem duas modalidades, uma é a empresa familiar e a outra é uma empresa empreendedora, que é definida de acordo com a geração que está no comando, conforme afirma Werner (2004), quando já estão presentes no negócio os herdeiros e sucessores, esta é denominada como empresa familiar, já a empresa empreendedora é aquela que seu fundador está em total domínio do empreendimento. Neste trecho o autor vem ressaltar que a empresa empreendedora está sobre a primeira geração e a empresa familiar aquela que está presente os possíveis sucessores.

\subsection{CICLO DE VIDA DE UMA EMPRESA}

Durante a trajetória de uma empresa ela passa por etapas conhecido como o ciclo de vida da empresa. E este é comparado com o ciclo de vida de um produto. De acordo com Lodi (apud LEONE, 2005, p. 59), "oferece grande poder explicativo, pois permite desdobrar em quatro fases a parábola da vida do fundador: fundação, crescimento, apogeu e declínio".

Nota-se que a empresa nasce, vive, desenvolve e decai desta forma, chegará o momento que seu fundador terá que pensar em quem dará andamento de seu negócio.

Podemos visualizar outra forma de destacar o ciclo de vida de uma empresa em relação ao processo sucessório, conforme demonstrado no gráfico. 
Figura 1 - "4" Estágios

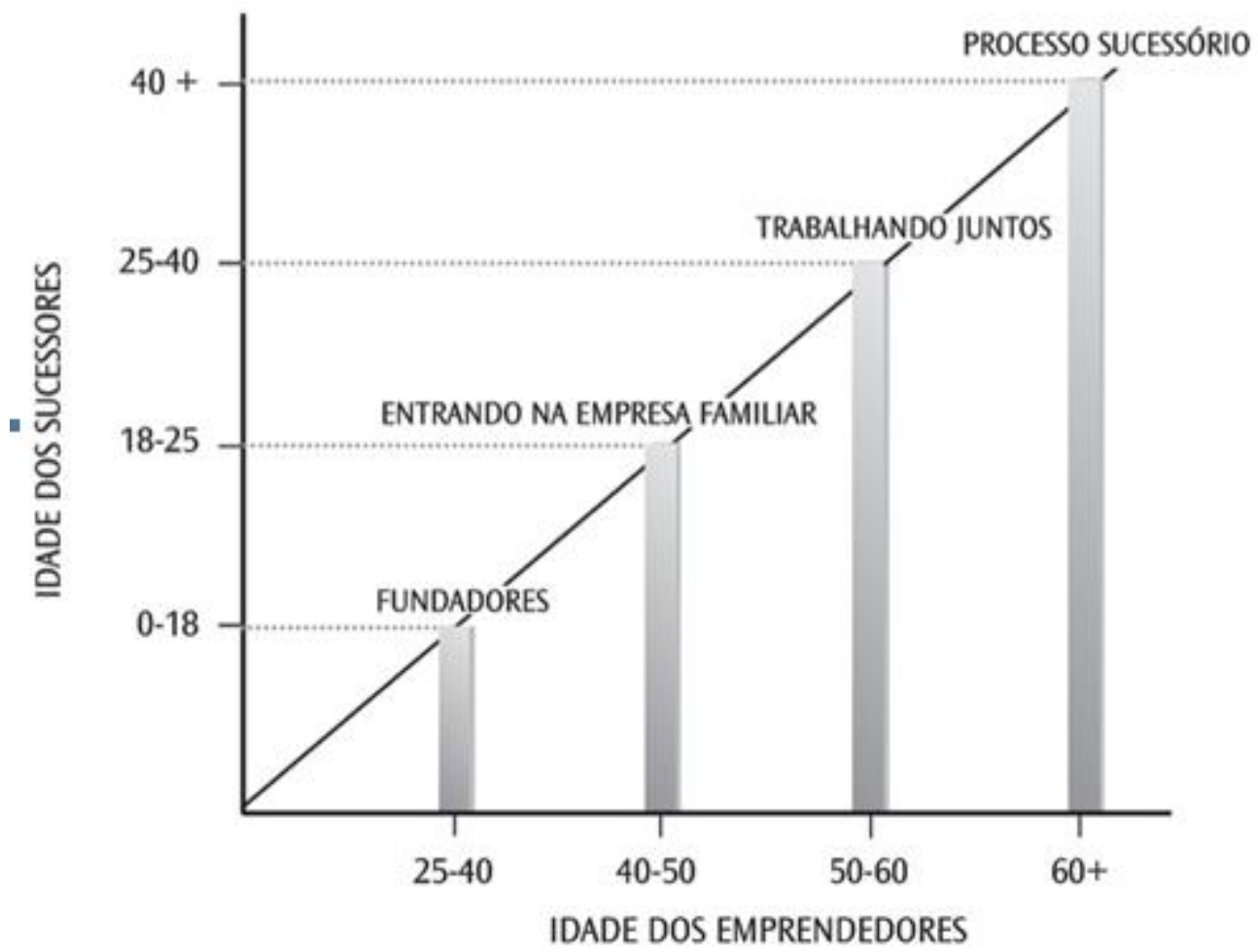

Fonte: Ombi (apud WERNER, 2004, p. 33)

A figura demonstra uma orientação que o empreendedor pode utilizar como base, para montar o plano de sucessão na sua empresa, analisando os possíveis sucessores da família ou já planejando a contratação de um profissional de administração para iniciar este processo de sucessão, assim, durante o ciclo de vida empresa ocorrem quatro estágios, mas o que define o processo sucessório é quando o fundador está com sessenta anos ou mais e o possível sucessor está com quarenta anos ou mais.

A sucessão de uma empresa é algo que seu fundador deve pensar ao longo dos anos pois, segundo Mamede (2014, p. 123) “[...] é indispensável preparar a família para a sucessão, ainda que isso implique trabalhar com a ideia da própria morte". Como se vê podem existir eventualidades na vida do fundador por isso sua família deverá ter consciência e pensar na possibilidade de substituição do mesmo.

O futuro sucessor necessita ser preparado previamente para assumir o negócio.

$$
\begin{aligned}
& \text { A formação dos } \\
& \text { sucessores, nesses } \\
& \text { ambientes, é um processo } \\
& \text { mais longo e para o qual } \\
& \text { se deve ter redobrada } \\
& \text { atenção para evitar que se } \\
& \text { verifiquem impactos } \\
& \text { negativos junto à clientela, }
\end{aligned}
$$

\begin{abstract}
fornecedores, bem como junto ao corpo de funcionários, resultado de uma completa ausência de vias de comunicação preexistentes. (MAMEDE, 2014 p.123).
\end{abstract}

Assim a preparação do sucessor leva certo tempo, por isso toda a empresa e seus envolvidos deverão ser comunicados para que se minimizem os danos gerados nesta transação.

\subsection{DIFICULDADES NO PROCESSO SUCESSÓRIO}

Por vários motivos os negócios podem gerar alguns problemas, de acordo com Moreira Junior (2011, p. 45), "Uma das principais dificuldades encontradas pela empresa familiar, quanto a sua sobrevivência no longo prazo, é a transferência do poder do fundador para seus possíveis sucessores." Por isso durante a passagem da empresa de uma geração para outra e eleger alguém para isso. Entretanto aquele que iniciou a empresa não encara a possibilidade de entregar o negócio ao sucessor, "[...] o fundador pode ter dificuldades de delegar e principalmente de passar o bastão; ou seja, apesar de repetidas promessas, o fundador se recusa a se aposentar." (OLIVEIRA, 2010, p.10, grifo autor). 
Com isso nesse período de escolha de um novo integrante para comandar a empresa, o fundador passa por inúmeras dificuldades que devem ser cuidadosamente trabalhadas para que possam ser superadas, assim, segundo Moreira Junior (2011, p. 63):

$$
\begin{aligned}
& \text { [...] as maiores } \\
& \text { dificuldades pelas quais as } \\
& \text { empresas passam no } \\
& \text { processo sucessório: falta } \\
& \text { de planejamento; preparo } \\
& \text { inadequado e grande } \\
& \text { número de herdeiros; } \\
& \text { conflitos familiares e } \\
& \text { divergências entre sócios; } \\
& \text { influência de funcionários, } \\
& \text { fornecedores, bancos e } \\
& \text { clientes; centralização do } \\
& \text { poder pelo fundador; } \\
& \text { herdeiros sem vocação ou } \\
& \text { com falta de interesse; } \\
& \text { dificuldade em escolher o } \\
& \text { sucessor; os fundadores } \\
& \text { dão mais importância ao } \\
& \text { fazer e não ao } \\
& \text { planejamento; os } \\
& \text { fundadores muitas vezes } \\
& \text { não acreditam nam } \\
& \text { capacidade dos filhos; os } \\
& \text { fundadores têm medo de } \\
& \text { ficar sem o comando da } \\
& \text { empresa; a relação do } \\
& \text { sucesso da empresa com a } \\
& \text { figura do fundador. }
\end{aligned}
$$

Desta forma, o empresário deverá lidar com esses inúmeros empecilhos que existem no período de escolha e passagem da empresa para o próximo dono, sendo algumas delas em não aceitar o fato de não ser mais o dono, não se programar para tal evento, e também o futuro dono não se identificar com o negócio e não se sentir capaz de comandar a empresa.

\subsection{PERFIL EMPREENDEDOR}

A fim de eleger quem será o futuro sucessor da empresa, este precisará ter o mesmo espírito empreendedor que o fundador teve, para assim sempre estar inovando os negócios da família, neste intuito, segundo Chiavenato, (2012, p. 3), "o empreendedor é a pessoa que inicia e/ou dinamiza um negócio para realizar uma ideia ou projeto pessoal assumindo riscos e responsabilidades e inovando continuamente." Desta forma um empreendedor sempre busca novidades e se dispõe a enfrentar todas as dificuldades.
O sucessor deverá ter qualidades compatíveis com um perfil empreendedor, que de acordo com os estudos realizados por Degen (2009, p.15):

[...] duas características
importantes necessárias
ao futuro empreendedor:
primeiro, não se
conformar com o mundo e
tentar adaptar o mundo a
si; segundo, ter grande
necessidade de realizar e
disposição de assumir os
riscos e fazer sacrifícios
pessoais necessários para
ter sucesso.

Mais uma vez nota-se que, o empreendedor além de buscar novas ideias, ele deve estar disposto em enfrentar todos os desafios de ser dono do próprio negócio. Por isso "o empreendedor é alguém especial, cujas características são reconhecidas e as qualidades foram essenciais para o surgimento da empresa. Toda a empresa familiar começa com o empreendedor, com alguém de visão" (WERNER, 2004 , p. 16). Assim, uma pessoa empreendedora consegue enxergar além e tomar as atitudes corretas através de várias habilidades, onde conseguirá conduzir seu próprio negócio.

No entanto, ele precisará não só empreender, mas também conseguir administrar a empresa. Pois segundo Schneider (2012, p.36):

O empreendedor é
alguém que precisa
saber gerenciar, de
forma equilibrada, não
só os aspectos usuais
de gestão- pessoal,
finanças, estoque,
entre outros- como
também as
informações, os
valores éticos e morais,
o tempo, as
tecnologias e as
relações pessoais e
profissionais.

Todavia ele terá que lidar com todos esses atributos exigidos de um gestor, para que ele consiga lidar melhor com a dinâmica do mercado e a empresa terem um bom desempenho. Entretanto, empreendedor e empresário possuem papeis diferentes.

Para Oliveira (2010, p. 9, grifo autor): 
Empreendedor é o que idealiza e constrói um negócio, que constitui uma nova empresa. Ou seja, dá origem a uma empresa familiar.

Empresário é o que consolida a empresa familiar, fazendo com que ela ultrapasse sua existência. Ou seja, ele procura a perpetuação da empresa familiar.

A diferença notada entre empreendedor e empresário, é que um cria uma nova idéia e ou negócio, o outro faz com que ele sobreviva ao longo do tempo.

No entanto durante a busca por um sucessor 0 fundador encontrará várias dificuldades, uma delas é encontrar no processo sucessório um herdeiro para que possa dar andamento na organização, "[...] a transição para os descendentes costuma ser um dos grandes problemas. Em certos casos, esse problema torna-se tão grave que causa a dissolução do negócio na segunda ou terceira geração" (MAXIMIANO, 2011, p.33). Sendo assim, no processo sucessório existem diversas dificuldades onde essas podem tornar o motivo de fechamento da empresa.

De acordo com Degen (2009, p.15), "Acontece que a grande maioria dos candidatos a empreendedor que não empreenderam ou não encontrou a ideia que valesse o sacrifício ou, se a encontrou, não está disposto a pagar o preço pessoal de leva - lá adiante". Contudo, a maior parcela de pessoas que podem ser colocadas na frente de um negócio, não se sente preparadas.

Já os sucessores que resolvem encaram o negócio de uma forma impensada, eles irão enfrentar desafios.

Conforme estudos realizados por Mamede (2014, p. 123): reconstituir os canais de comunicação, restabelecer as relações internas e externas etc.

Os herdeiros da empresa terão que aprender a gerir a empresa da família de acordo com as rotinas administrativas, obtendo uma interação com todos os envolvidos e manutenção das atividades empresariais, para assim restabelecer o controle. Entretanto,

segundo Dornelas (2015), as empresas familiares empreendedoras tem a capacidade de identificar o sucessor e este levará adiante os negócios da família.

Quando não existe a possibilidade de encontrar na família o sucesso, o fundador pode ter outra opção para dar seguimento ao empreendimento, "a sucessão familiar é a que tem recebido maior ênfase nas empresas familiares, mas deve-se considerar a sucessão profissional como em significativa evolução nas referidas empresas." (OLIVEIRA, 2010, p. 12). As empresas devem ter a percepção que quando não existe um membro da família que consiga prosseguir com o negócio deverá procurar um profissional, para que este de continuidade ao empreendimento.

\section{APRESENTAÇÃO E ANÁLISE DOS DADOS}

Neste capítulo são apresentados às análises sobre os dados coletados em uma empresa do segmento alimentício na Região de Presidente Prudente, que já está no mercado há aproximadamente 20 anos. Para melhor compreensão, as análises foram organizadas a partir de dois eixos: no primeiro eixo foi analisado o questionário aplicado fundador e o no segundo eixo questionário aplicado à sucessora.

\subsection{QUESTIONÁRIO APLICADO AS FUNDADOR}

Ao perguntar para o fundador porque ele decidiu montar seu próprio negócio ele disse que: Sempre trabalhei no comércio e teve vontade de ser dono do próprio negócio, quando fui mandado embora do meu trabalho aproveitei meu acerto para investir nesse sonho.

Segundo Schneider os empreendimentos podem ser iniciados em duas maneiras, por necessidades que é para o sustento de sua família e o de oportunidades, que é quando se detecta uma ideia de negócio e a inicia através de um planejamento. 
Ao questionar sobre a escolha do segmento, o fundador fez o seguinte relato: $\mathrm{Na}$ época existiam muitos bares na redondeza $e$ poucas mercearias, então decidi investir o dinheiro do meu acerto para trabalhar por conta própria.

Conforme citado na pesquisa por Werner que, o empresário é alguém visionário e/ou empreendedor que consegue identificar a oportunidade para montar seu próprio negócio, onde ele ao longo do tempo a desenvolve e faz crescer.

Em relação à preparação para iniciar e montar seu próprio negócio o empresário disse que: Não fiz nenhuma preparação, pois a abertura da empresa foi uma necessidade de momento e acabei montando a empresa sem ter um estudo inicial.

Conforme citado por Schneider o início da empresa por ser gerada por vários motivos, necessidade ou oportunidades, os iniciados por necessidade são aqueles feitos sem nenhum planejamento, somente tem como objetivo de melhorar a condição socioeconômica de sua família, mas muitas vezes está falta de planejamento pode acabar decretando o fechamento da empresa, pois são muitos os risco que $o$ fundador assume ao não ter um planejamento inicial, a maneira correta para se iniciar a empresa mesmo na necessidade seria avaliar os riscos e oportunidades para que o fundador já tenha uma visão geral dos riscos que ele pode ter ao iniciar a empresa, sendo assim ele estará mais preparados para poder resolver estes problemas.

Questionou-se o fundador quais são seus projetos futuros para a empresa ele respondeu que: Quero dar continuidade a minha mercearia, passando para meus filhos.

Conforme relatado por Lodi apud Leone no capítulo do Ciclo de Vida da Empresa, que em uma determinada etapa da empresa familiar, depois que o fundador a criou, a desenvolveu começa a surgir à necessidade de pensar em seu substituto, onde ele deseja que um dia um de seus familiares consiga dar sequencia a sua empresa.

Quando perguntamos para o proprietário como tem se preparado para o processo sucessório dentro da empresa, e como ele tem preparado seus sucessores, fez o seguinte relato: Estou ensinando no dia a dia o que sei para minha filha.
Mamede cita que a família deve ser preparada para a sucessão, sendo isso um processo longo e para que não ocorram impactos negativos mediante as possíveis eventualidades, desta maneira o fundador deve se planejar para tal acontecimento. Assim o sucessor deve ser preparado previamente pois isso é um processo longo.

Quanto às dificuldades encontradas em relação ao processo sucessório o empresário disse que: Tenho dois filhos um não demonstra interesse $e$ não está mais trabalhando na empresa e a outra está me ajudando, mas tem medo de assumir e eu também fico com medo de saber se ela vai dar conta.

Conforme relatado por Moreira Junior, sobre as dificuldades existentes no processo sucessório uma das principais seria a transferência da empresa para um herdeiro, que isso será a garantia da sobrevivência da mesma ao longo prazo, mas a frente o autor ressalta que a falta de planejamento e a falta de preparo do futuro sucessor devem ser cuidadosamente trabalhadas para que essas dificuldades sejam superadas. Este planejamento e preparo seriam essenciais para que o novo dono tenha confiança.

Já Oliveira aborda sobre outra dificuldade que é o fundador não conseguir aceitar o fato de eu afastamento. Neste objeto de estudo nota-se que o dono tem dúvida da capacidade do sucessor se ele vai conseguir dar andamento a empresa. Dornelas fala que as empresas familiares empreendedoras tem a capacidade de identificar o sucessor e este levará adiante os negócios da família.

\subsection{QUESTIONÁRIO APLICADO A SUCESSORA}

A provável sucessora já está atuando na empresa há alguns anos com o intuito de identificar se ela possui perfil empreendedor.

Ao questionarmos se ela se identifica com o segmento da empresa ela respondeu: Sim. Porque já me acostumei e vejo que é um negócio bom porque comida as pessoas não deixam de comprar.

De acordo com a pesquisa Degen diz que o sucessor precisará ter o mesmo espírito empreendedor que o fundador, o sucessor deverá ter qualidades compatíveis com um perfil empreendedor, para conseguir inovar em seu negócio e também superar todos os desafios inerentes de um empresário, mas também pode ter a possibilidade de nem sempre os sucessores se identificam com o tipo de negócio do 
fundador, pois muitas vezes não atendem as expectativas e não tem características para dirigir a empresa, ou não se identificam com o cargo a que está sendo repassado, por não possuir o espírito empreendedor, sendo estes fatores indispensáveis para a continuidade do negócio, portanto a empresa entrevista é uma empresa que está conseguindo seguir no caminho certo, pois umas das grandes dificuldades ele já conseguiu sanar, pois a sucesso já se identifica com o ramo de atividade da empresa.

Quando foi perguntado se ela se sente preparada para assumir a empresa de sua família ela respondeu: Sim. Já estou acostumada com tudo porque tem bastante tempo que ajudo meu pai por isso me sinto preparada.

Em contrapartida em relação a este assunto Mamede comenta que o sucessor não possui nenhum preparo, mas que demonstra ser capaz de gerir o negócio, este gastará muito tempo consertando os erros devido à falta de experiência, até entender como funcionam todos os processos. Para Mamede apesar de o sucessor despreparado revelar uma surpreendente capacidade de gestão, há um gasto de tempo e um volume de erros no processo necessário para entender as rotinas de produção e administração, inteirar-se da logística de funcionamento, reconstituir os canais de comunicação, restabelecer as relações internas e externas etc.

Os sucessores herdeiros da empresa terão que aprender a gerir a empresa da família de acordo com as rotinas administrativas, obtendo uma interação com todos os envolvidos e manutenção das atividades empresariais, para assim restabelecer o controle.

Em relação às características necessárias para tornar um empreendedor de sucesso ela fez o seguinte relato: Adquirir experiência profissional gostaria voltar estudar para me preparar melhor, mas por causa da minha gravidez tive que esperar um pouco.

Para Oliveira o melhor caminho para que qualquer empreendimento sobreviva no mercado é a profissionalização do serviço que seria alguém contratado para tal serviço, se acaso o fundador não o encontrar dentro da família, neste caso ela se sente preparada poderia ela procurar se capacitar através de uma faculdade ou pelo menos cursos técnicos específicos da área. Degen também relata que existem duas características importantes necessárias ao futuro empreendedor: primeiro; não se conformar com o mundo e tentar adaptar o mundo a si; segundo, ter grande necessidade de realizar e disposição de assumir os riscos e fazer sacrifícios pessoais necessários para ter sucesso.

Quanto aos desafios e dificuldades foram perguntados quais ela enfrenta e como faz para melhorar, ela disse: Faço muitas coisas ao mesmo tempo, não tendo muito tempo para ficar na parte administrativa, procuro fazer o que faço bem perfeito para melhorar.

Conforme relatado por Degen no capítulo do perfil empreendedor, este deverá assumir riscos e sempre estar buscando algo novo para a organização. Já Schneider acrescenta que o empreendedor deve também gerir todas as áreas da empresa de forma equilibrada, como gestão de pessoas, tecnologias, estoque, finança, dentre outras. E por fim Oliveira fala que empreendedor e empresário possuem papeis diferentes o primeiro é aquele que cria algo novo e um empresário que consiga fazer que a empresa através de uma boa gestão consolide ao longo do tempo. Desta forma é claro perceber que o sucessor necessitará fazer a junção desses papeis para a perpetuação da empresa.

\section{CONSIDERAÇÕES FINAIS}

A empresa familiar possui um importante papel dentro da sociedade e tem demonstrado cada vez mais presente e em crescimento dentro do mercado, pois muitas pessoas tem buscado a realização de montar o seu próprio negócio para deixar de ser empregado. E uma forma de perpetuar este sonho é se utilizar de membros da própria família para dar continuidade. Desta forma o fundador deverá se planejar para tal acontecimento para que diminua o risco de seu negócio fechar.

O artigo traz uma visão em relação à empresa familiar e seus sucessores, foram expostas várias opiniões onde alguns encontram dificuldades e outras já tem o sucessor, a empresa analisada não teve muita dificuldade para encontrar o seu sucessor, pois o mesmo já trabalha dentro da organização, e também já está se preparando para poder assumir os negócios da família, uma posição que mostra uma visão diferente da que foi imaginada no início da pesquisa, pois se acreditava que a maioria das empresas teriam dificuldades e não teriam um sucessor para prosseguir com os negócios.

Diante do exposto, o objetivo proposto para o presente artigo se fez atingido, pois conseguiu identificar algumas das dificuldades que as empresa encontram durante o processo 
sucessório, sendo elas, falta de planejamento do fundador, não acreditar na capacidade do herdeiro de assumir o negócio e o preparo inadequado do mesmo para tal acontecimento.

Também se conseguiu identificar que o possível sucessor tem o perfil empreendedor e que pode dar continuidade com o negócio da família para que ele possa expandir e aumentar a lucratividade da empresa, porém é importante ressaltar necessidade do sucessor em se qualificar profissionalmente.

Para a empresa estuda fica a sugestão de continuar no mesmo caminho utilizado até agora para manter-se dentro do mercado, buscando sempre a inovação para o melhor atendimento ao cliente e se utilizar de novas ideias para o negócio, poderia também o fundador buscar uma especialização para o sucessor onde o mesmo pode se especializar através de ferramentas administrativas, com isso nas dificuldades ele estará mais bem preparado para poder passar por esses problemas sem sofrer tanto e também que possa sempre buscar a melhor opção para o futuro da empresa. Outra opção é profissionalizar o negócio, contratando alguém para administrar a empresa.

Por fim, com o presente artigo espera ter contribuído para novas pesquisas relacionadas a este assunto, lembrando que este tema sobre empresa familiar ainda não está esgotado, fica a sugestão para novas pesquisas, buscar os novos modelos de empresas familiares que possam surgir com a evolução da tecnologia, e verificar se nestas empresas o empreendedor terá o mesmo perfil do empreendedor tradicional ou se ele já terá uma visão completamente diferente do empreendedor tradicional que conhecemos até os dias de hoje.

\section{REFERÊNCIAS}

ALMEIDA, A. P. et al. Comentários ao estatuto da microempresa e da empresa de pequeno porte: lei complementar n. 123/2006: lei complementar n. 127/2007. São Paulo: Saraiva, 2009.

CHIAVENATO, I. Empreendedorismo: dando asas ao espírito empreendedor. 4. ed. Barueri: Manole, 2012.

DEGEN, R. J. O empreendedor: empreender como opção de carreira. São Paulo: Pearson Prentice Hall, 2009.

DORNELAS, J. C. A. Empreendedorismo na prática: mitos e verdades do empreendedor de sucesso. 3. ed. Rio de Janeiro: LTC, 2015.
GIL, A. C. Métodos e técnicas de pesquisa social. 6. ed. São Paulo: Atlas, 2012.

LAKATOS, E. M.; MARCONI, M. A.; Fundamentos de metodologia cientifica. 7. ed. São Paulo : Atlas, 2010.

LEONE, N. M. C. P. G. Sucessão na empresa familiar: preparando as mudanças para garantir sobrevivência no mercado globalizado. São Paulo: Atlas, 2005.

MAMEDE, G. Empresas familiares: o papel do advogado na administração, sucessão e prevenção de conflitos entre sócios. 2 ed. São Paulo: Atlas, 2014.

MASCARENHAS, S. A. Metodologia científica. São Paulo: Pearson Education Brasil, 2012.

MAXIMIANO, A. C. A. Administração para empreendedores: fundamentos para criação e da gestão de novos negócios. 2 ed. São Paulo: Pearson Prentice Hall, 2011.

MAXIMIANO, A. C. A. Empreendedorismo: São Paulo: Person Prentice Hall, 2012,

MOREIRA, J. A. L. Empresa Familiar: um sonho realizado. São Paulo: Saraiva, 2011.

OLIVEIRA, D. P. R. Empresa familiar: a jornada de transformação dos sonhos em realidade. 3. ed. São Paulo: Atlas, 2010.

SEBRAE, SP. Pequenos negócios em números Disponível em: <http://www.sebraesp.com.br/index.php/234unc ategorised/institucional/pesquisas-sobre-microe-pequenas-empresas-paulistas/micro-epequenas-empresas-em-numeros $>$. Acesso em: 31 out. 2016.

SEBRAE, SP. Minha empresa é familiar e agora? Disponível em: <http://www.sebraesp.com.br/index.php/compo nent/content/article/48-

noticias/planejamento/16701-planejamento-e-achave-para-uma-sucessao-familiar-sem-risco-naempresa>. Acesso em: 31 out. 2016

SCNEIDER, E. I. A caminhada empreendedora: a jornada de transformação dos sonhos em realidade. Curitiba: Intersaberes, 2012.

WANKE, Peter F. Logística para micro e pequenas empresas São Paulo: Atlas, 2012.

WERNER, R. A. Família \& Negócios: Um caminho para o sucesso. São Paulo: Manole, 2004.

Recebido para publicação em 09/08/2017

Revisado em 15/08/2017

Aceito em 26/08/2017 